\title{
Oceanithermus profundus gen. nov., sp. nov., a thermophilic, microaerophilic, facultatively chemolithoheterotrophic bacterium from a deep-sea hydrothermal vent
}

\author{
M. L. Miroshnichenko, ${ }^{1}$ S. L'Haridon, ${ }^{2}$ C. Jeanthon, ${ }^{2}$ A. N. Antipov, ${ }^{3}$ \\ N. A. Kostrikina, ${ }^{1}$ B. J. Tindall, ${ }^{4}$ P. Schumann, ${ }^{4}$ S. Spring, ${ }^{4}$ E. Stackebrandt ${ }^{4}$ \\ and E. A. Bonch-Osmolovskaya ${ }^{1}$ \\ ${ }^{1}$ Institute of Microbiology, Russian Academy of Sciences, Prospect 60-letiya Oktyabrya 7/2, \\ 117811 Moscow, Russia \\ ${ }^{2}$ UMR 6539, Centre National de la Recherche Scientifique and Université de Bretagne \\ Occidentale, Institut Universitaire Européen de la Mer, 29280 Plouzané, France \\ ${ }^{3}$ A. N. Bach Institute of Biochemistry, Russian Academy of Sciences, Leninsky Prospect 33, \\ 119071 Moscow, Russia \\ ${ }^{4} \mathrm{DSMZ}$ - German Collection of Microorganisms and Cell Cultures, Mascheroder Weg 1b, \\ 38124 Braunschweig, Germany
}

Correspondence

M. L. Miroshnichenko alfamirr@mail.ru
A novel moderately thermophilic, organotrophic, microaerophilic, facultatively chemolithotrophic bacterium, designated strain $506^{\top}$, was isolated from a deep-sea hydrothermal vent site at $13^{\circ} \mathrm{N}$ in the East Pacific Rise. Cells were Gram-negative, non-motile rods. The organism grew in the temperature range $40-68^{\circ} \mathrm{C}$, with an optimum at $60^{\circ} \mathrm{C}$, and in the $\mathrm{pH}$ range $5 \cdot 5-8 \cdot 4$, with an optimum around $\mathrm{pH} 7 \cdot 5$. The $\mathrm{NaCl}$ concentration for growth was in the range $10-50 \mathrm{~g} \mathrm{I}^{-1}$, with an optimum at $30 \mathrm{~g} \mathrm{I}^{-1}$. Strain $506^{\top}$ grew chemoorganoheterotrophically with carbohydrates, proteinaceous substrates, organic acids and alcohols using oxygen or nitrate as electron acceptor. Alternatively, strain $506^{\top}$ was able to grow lithoheterotrophically with molecular hydrogen as the energy source. The $\mathrm{G}+\mathrm{C}$ content of the genomic DNA was $62.9 \mathrm{~mol} \%$. Phylogenetic analysis of the $16 \mathrm{~S}$ rDNA sequence placed strain $506^{\top}$ in the family Thermaceae. On the basis of phenotypic and phylogenetic data, strain $506^{\top}$ (=DSM $14977^{\top}=$ VKM B-2274 ${ }^{\top}$ ) is proposed as the type strain of a novel species in a new genus, Oceanithermus profundus gen. nov., sp. nov.
The family Thermaceae currently comprises thermophilic, rod-shaped organisms with a strictly respiratory type of metabolism. The first representative, Thermus aquaticus, was isolated from a hot spring in Yellowstone National Park (Brock \& Freeze, 1969), but representatives of this group have been found in many natural and artificial thermal habitats (Williams \& Da Costa, 1992). At the time of writing, the genus Thermus is represented by eight species with high optimal growth temperatures $\left(65-75^{\circ} \mathrm{C}\right)$, while four species with lower temperature optima $\left(50-65^{\circ} \mathrm{C}\right)$ are classified in the genus Meiothermus (Nobre et al., 1996). A new genus, Marinithermus, has recently been described; its unique representative, Marinithermus hydrothermalis, isolated from a deep-sea hydrothermal vent, thrives between 50 and

Published online ahead of print on 4 October 2002 as DOI 10.1099/ ijs.0.02367-0.

The GenBank accession number for the 16S rRNA gene sequence of strain $506^{\top}$ is AJ430586.
$72 \cdot 5^{\circ} \mathrm{C}$ (optimum $67 \cdot 5^{\circ} \mathrm{C}$ ) (Sako et al., 2003). Most strains of the family Thermaceae are organotrophs, though the ability to grow lithotrophically with sulfur compounds was reported for Thermus scotoductus (Skirnisdottir et al., 2001). Some strains are also able to grow anaerobically with nitrate or nitrite as the terminal electron acceptor (Da Costa \& Rainey, 2001). In this paper, we report the isolation, from a deep-sea hydrothermal vent, of a novel microaerophilic representative of the family Thermaceae that is capable of lithotrophic and organotrophic growth.

Samples were collected during the Amistad cruise (1999) at the $13^{\circ} \mathrm{N}$ hydrothermal vent field $\left(12^{\circ} 48^{\prime} \mathrm{N}, 103^{\circ} 56^{\prime} \mathrm{W}\right)$ on the East Pacific Rise at a depth of $2600 \mathrm{~m}$. Samples of hydrothermal fluids and chimneys were transferred in tightly stoppered $50 \mathrm{ml}$ plastic tubes and stored at $4{ }^{\circ} \mathrm{C}$. The enrichment medium contained the following $\left(\mathrm{g} \mathrm{l}^{-1}\right.$ unless indicated): $\mathrm{NH}_{4} \mathrm{Cl}, 0.33 ; \mathrm{KCl}, 0.33 ; \mathrm{KH}_{2} \mathrm{PO}_{4}$, $0.33 ; \mathrm{CaCl}_{2} .2 \mathrm{H}_{2} \mathrm{O}, 0.33 ; \mathrm{MgCl}_{2} \cdot 6 \mathrm{H}_{2} \mathrm{O}, 0 \cdot 33 ; \mathrm{NaCl}, 25 \cdot 0$; 
$\mathrm{NaNO}_{3}, 3 \cdot 0$, sodium acetate, $3 \cdot 0$, yeast extract, $0 \cdot 1$; $\mathrm{NaHCO}_{3}, \quad 0 \cdot 5$; trace elements (Balch et al., 1979), $10 \mathrm{ml} \mathrm{l}^{-1}$; vitamins (Wolin et al., 1963), $10 \mathrm{ml} \mathrm{l}^{-1}$. The medium was prepared anaerobically (Balch et al., 1979) and dispensed into $15 \mathrm{ml}$ Hungate tubes; the headspace $(5 \mathrm{ml})$ was filled with $\mathrm{N}_{2}$ (atmospheric pressure). No reducing agents were added to the medium. The $\mathrm{pH}$ of the medium was 6.5 . Single colonies were isolated using the same medium solidified with $1.5 \%$ agar (Difco) by using a serial 10-fold dilution technique in agar shake tubes. Agar shake tubes were incubated at $60^{\circ} \mathrm{C}$ for 5 days. The morphology of the novel isolate was examined using a light microscope (Mikmed-1 model; LOMO). The ultrastructure of whole cells and thin sections was studied as described elsewhere (Bonch-Osmolovskaya et al., 1990). Oxidase activity was assayed with discs impregnated with dimethyl p-phenylenediamine (bioMérieux). Catalase activity was assayed by mixing a pellet of a freshly centrifuged culture with a drop of hydrogen peroxide $(10 \%, \mathrm{v} / \mathrm{v})$. Physiological tests were performed in BM medium, which consisted of enrichment medium from which the sodium acetate and sodium nitrate had been omitted. Potential proteinaceous growth substrates were added to the $\mathrm{BM}$ medium at a concentration of $1 \mathrm{~g} \mathrm{l}^{-1}$; carbohydrates, sodium salts of organic acids and alcohols were present at a concentration of $3 \mathrm{~g} \mathrm{l}^{-1}$. When molecular hydrogen served as the substrate, the headspace $(10 \mathrm{ml})$ was filled with a $\mathrm{H}_{2} / \mathrm{CO}_{2}$ mixture $(4: 1, \mathrm{v} / \mathrm{v})$. Possible electron acceptors were added at a concentration of $2 \mathrm{~g} \mathrm{l}^{-1}$. All experiments were performed in triplicate.

To determine the ability to grow microaerophilically, air was added to the headspace $(10 \mathrm{ml})$ of tubes filled with BM medium $(5 \mathrm{ml})$. The final oxygen concentration was varied from 0.5 to $9 \%$. The ability to grow aerobically was determined either on plates with agarized BM medium (2\% agar; Difco) supplemented with sucrose $\left(2 \mathrm{~g} \mathrm{l}^{-1}\right)$ and tryptone $\left(1 \mathrm{~g} \mathrm{l}^{-1}\right)$ or in $100 \mathrm{ml}$ flasks containing the same medium $(10 \mathrm{ml})$. Growth was monitored by measuring the increase in $\mathrm{OD}_{600}$ by using a Spectronic 401 spectrophotometer (Bioblock). All growth experiments were performed in duplicate using Bellco tubes under microaerophilic conditions. The $\mathrm{pH}$ range for growth was determined in BM medium supplemented with $2 \mathrm{~g}$ sucrose and $2 \mathrm{~g}$ sodium nitrate $\mathrm{l}^{-1}$ using various buffers (MES for $\mathrm{pH} 5 \cdot 0-6 \cdot 0$, PIPES for $\mathrm{pH} 6 \cdot 5$ and $7 \cdot 0$, HEPES for $\mathrm{pH} 7 \cdot 5$, Tris for $\mathrm{pH} 8.0$ and 8.5 ) at a concentration of $10 \mathrm{mM}$. Appropriate amounts of $1 \mathrm{M} \mathrm{Na}_{2} \mathrm{CO}_{3}$ were added to adjust the $\mathrm{pH}$ of the medium to $9 \cdot 0$ and $9 \cdot 5$. The $\mathrm{pH}$ was determined at room temperature. To determine the optimum $\mathrm{NaCl}$ range for growth, $\mathrm{NaCl}$ concentrations were varied while the concentrations of the other inorganic components were maintained. The effects of different $\mathrm{pH}$ values and concentrations of $\mathrm{NaCl}$ were determined at $60^{\circ} \mathrm{C}$. Gaseous and liquid fermentation products were detected by means of GLC (Miroshnichenko et al., 1994). Gaseous and liquid products of nitrate reduction were studied as described elsewhere (Miroshnichenko et al., 2003). Respiratory quinones and polar lipids were extracted and analysed as described previously (Tindall, 1990a, b). Fatty acids were extracted and analysed as methyl esters as described previously. The presence of unsaturation was confirmed by hydrogenation (Brian \& Gardner, 1968) and the position of unsaturation was located by the formation of dimethyl disulfide adducts, using the method of Nichols et al. (1986) and the instrumentation and conditions described previously (Strömpl et al., 1999).

DNA was isolated after disruption of cells using a French pressure cell (Thermo Spectronic) and purified by hydroxyapatite chromatography (Cashion et al., 1977). The DNA was hydrolysed with P1 nuclease and the nucleotides were dephosphorylated with bovine alkaline phosphatase (Mesbah et al., 1989). The resulting deoxyribonucleosides were analysed by HPLC as described by Tamaoka \& Komagata (1984). Genomic DNA extraction, PCR-mediated amplification of the 16S rDNA and sequencing of PCR products were carried out as described by Rainey et al. (1996). Purified PCR products were sequenced directly using a Taq Dye-Deoxy Terminator cycle sequencing kit (Applied Biosystems) according to the manufacturer's instructions. An Applied Biosystems 310 DNA Genetic Analyzer was used for electrophoresis of sequence reaction products. The $16 \mathrm{~S}$ rDNA sequence of strain $506^{\mathrm{T}}$ was aligned manually with nucleotide sequences obtained from the GenBank and EMBL databases. The method of Jukes \& Cantor (1969) was applied to calculate evolutionary distances. Phylogenetic trees were constructed using the methods of DeSoete (1983) and Felsenstein (1993).

Twelve samples from hydrothermal vents containing water and chimney material were used for the inoculation of enrichment medium $(5 \%, \mathrm{v} / \mathrm{v})$ and incubated at $60^{\circ} \mathrm{C}$. After 5 days incubation, samples of the inner and outer chimney part from the 'Genesis' site produced abundant growth of morphologically homogeneous micro-organisms. After several successive transfers, the enrichment culture was serially diluted and the highest dilutions were transferred to the same medium solidified with agar. After 5 days incubation at $60^{\circ} \mathrm{C}$, single colonies appeared. Colonies were spherical and non-pigmented, with diameters ranging from $0 \cdot 3$ to $1 \mathrm{~mm}$. A single colony from the last dilution was transferred into liquid enrichment medium. The purification procedure was repeated twice, after which the culture was considered to be pure. Purity was confirmed by microscopic examination of the culture growing on medium containing glucose $\left(3 \mathrm{~g} \mathrm{l}^{-1}\right)$, pyruvate $\left(3 \mathrm{~g} \mathrm{l}^{-1}\right)$ and yeast extract $\left(3 \mathrm{gl}^{-1}\right)$. The purified micro-organism was designated as strain $506^{\mathrm{T}}$.

Cells of strain $506^{\mathrm{T}}$ were non-motile rods, $0 \cdot 5-0 \cdot 7 \mu \mathrm{m}$ in diameter and of various lengths. On negatively stained electron microscope preparations, small spheres were often seen along the cell wall and between the cells (Fig. 1a). Flagella were never observed. When grown on proteinaceous substrates, old cultures of strain $506^{\mathrm{T}}$ formed filaments and large spheres (Fig. 1c) resembling the 'rotund bodies' typical 

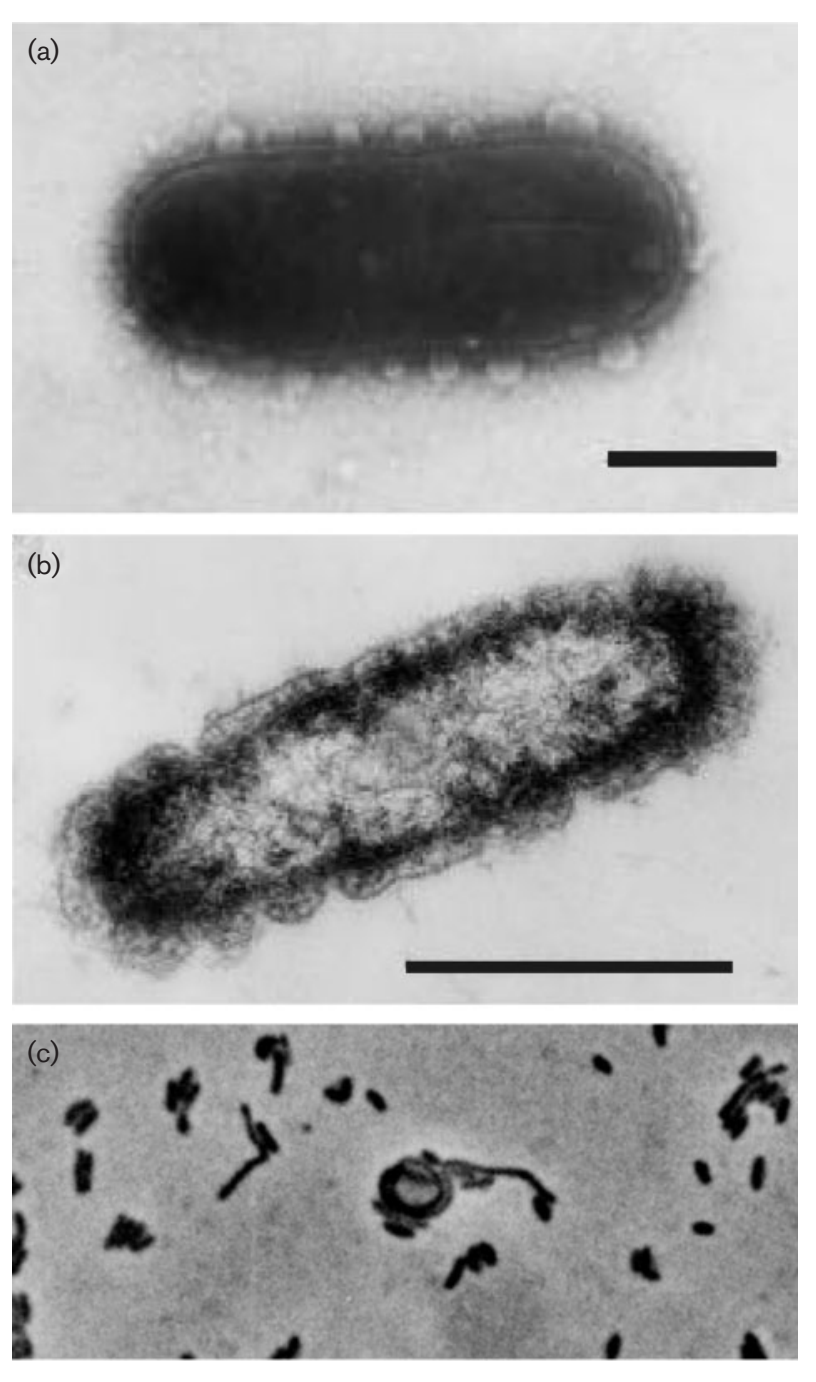

Fig. 1. Negatively stained whole cell (a), thin section of a whole cell (b) and phase-contrast micrograph (c) of strain $506^{\top}$. Bars, $0.5 \mu \mathrm{m}$.

of aged cells of Thermus species (Brock \& Edwards, 1970). Thin-section electron micrographic preparations revealed a Gram-negative cell wall structure. The cell wall had a complex multilayered structure with a characteristic corrugated outer layer (Fig. 1b). Spores were never observed. The isolate was microaerophilic, only being able to grow at oxygen concentrations below $6 \%$. No growth was observed in an atmosphere of air, either in liquid medium or on plates. In an agar tube (containing $5 \mathrm{ml} \mathrm{BM}$ medium supplemented with $2 \mathrm{~g}$ sucrose and $1 \mathrm{~g}$ tryptone $\mathrm{l}^{-1}$ ) with air in the headspace $(10 \mathrm{ml})$, growth occurred only in a zone located $20 \mathrm{~mm}$ below the agar/air interface. Alternatively, strain $506^{\mathrm{T}}$ grew anaerobically using nitrate as the electron acceptor. Strain $506^{\mathrm{T}}$ grew within a temperature range of $40-68{ }^{\circ} \mathrm{C}$, optimal growth being observed at $60{ }^{\circ} \mathrm{C}$. At $60^{\circ} \mathrm{C}$, it grew between $\mathrm{pH} 5 \cdot 5$ and $8 \cdot 4$, with an optimum around 7.5. Strain $506^{\mathrm{T}}$ required $\mathrm{NaCl}$ for growth and grew at $\mathrm{NaCl}$ concentrations ranging from 10 to $50 \mathrm{~g} \mathrm{l}^{-1}$, with an optimum at $30 \mathrm{~g} \mathrm{l}^{-1}$. Strain $506^{\mathrm{T}}$ was oxidase- and catalasepositive. It was able to utilize a wide spectrum of carbohydrates in the presence of either nitrate or oxygen. The highest cell yield was observed in the presence of nitrate with fructose, maltose, sucrose, trehalose, galactose, rhamnose or xylose. It also utilized glucose, lactose and starch, but did not grow with ribose, galactose, arabinose, dextrin or cellobiose. Acetate and propionate were produced during growth with sucrose as a growth substrate and nitrate as the electron acceptor. Nitrite was the only product of denitrification. Strain $506^{\mathrm{T}}$ grew well with complex proteinaceous substrates such as beef extract, tryptone or papaic digest of soybean $\left(1-1 \cdot 5 \mathrm{~g} \mathrm{l}^{-1}\right)$. However, growth was strongly inhibited by higher concentrations of these substrates. The isolate did not grow with Casamino acids or yeast extract as sole sources of carbon and energy, though $100 \mathrm{mg}$ yeast extract $\mathrm{l}^{-1}$ was required for growth. Strain $506^{\mathrm{T}}$ was able to utilize acetate, pyruvate and propionate as growth substrates. It also grew with methanol, ethanol and mannitol, though the cell yield was lower. Strain $506^{\mathrm{T}}$ was able to grow lithoheterotrophically using molecular hydrogen as the energy source, yeast extract as the carbon source and nitrate as the electron acceptor. Other electron acceptors (sulfate, elemental sulfur, thiosulfate, nitrite) did not support growth, regardless of growth substrate.

Menaquinones were the sole respiratory lipoquinones detected, with MK-8 predominating (95\%) and MK-9 being present in smaller proportions (5\%). The fatty acids comprised mainly iso- and anteiso-branched fatty acids; isounsaturated fatty acids were also present (Table 1). The polar lipid pattern was fairly simple, comprising only phospholipids; glycolipids were not detected (Fig. 2). The major phospholipid had an $R_{\mathrm{f}}$ value identical to that of the

Table 1. Fatty acid composition of strain $506^{\top}$

\begin{tabular}{|lc|}
\hline Fatty acid & Percentage of total \\
\hline iso $14: 0$ & $1 \cdot 0$ \\
iso $15: 1 \omega 7^{\star} \dagger$ & $7 \cdot 7$ \\
iso $15: 0$ & $33 \cdot 2$ \\
anteiso $15: 0$ & $5 \cdot 1$ \\
$15: 0$ & $1 \cdot 3$ \\
iso $16: 1 \omega 8 \dagger$ & $2 \cdot 6$ \\
iso $16: 0$ & $1 \cdot 5$ \\
$16: 0$ & $3 \cdot 3$ \\
iso $17: 1 \omega 7$ cis & $18 \cdot 8$ \\
iso $17: 1 \omega 9$ cis/ $\omega 7$ trans & $1 \cdot 4$ \\
iso $17: 1 \neq$ & $1 \cdot 0$ \\
iso $17: 0$ & $12 \cdot 3$ \\
anteiso $17: 0$ & $5 \cdot 4$ \\
$18: 0$ & $1 \cdot 5$ \\
iso $19: 1 \omega 7 \dagger$ & $1 \cdot 1$ \\
\hline
\end{tabular}

${ }^{\star}$ May comprise two overlapping compounds.

$\dagger$ Cis/trans configuration not determined.

$\ddagger$ Location of the double bond not determined. 


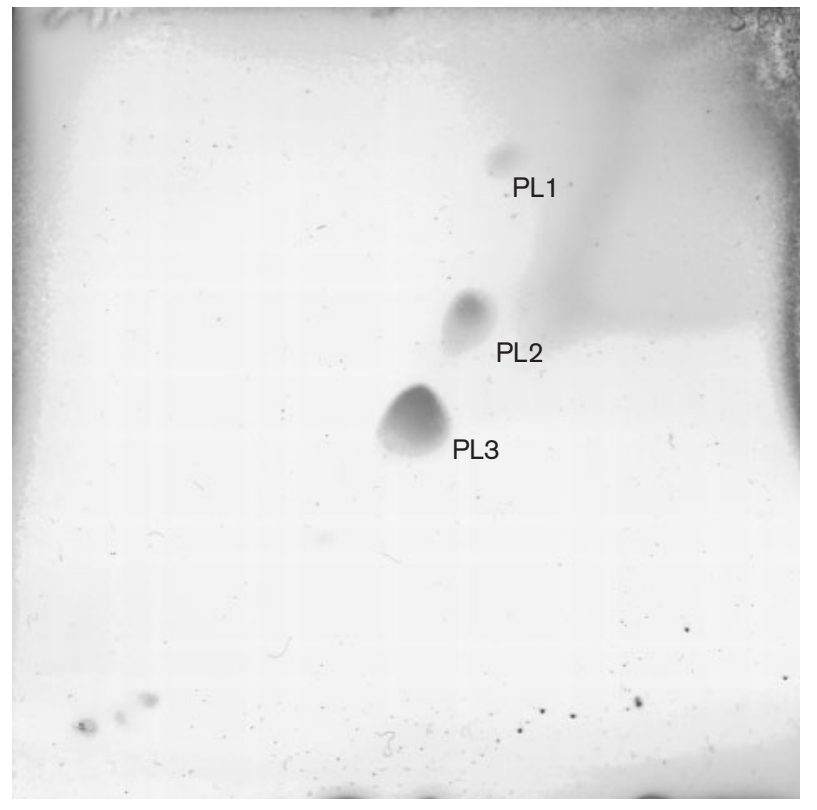

Fig. 2. Polar lipid composition of strain $506^{\top}$. Separation in two dimensions: first dimension, chloroform/methanol/water ( $65: 25: 4$, by vol.); second dimension, chloroform/methanol/ acetic acid/water ( $80: 12: 15: 4$, by vol.). Identification of the polar lipids was achieved using spray reagents as described in the text. PL1, PL2 and PL3 indicate unidentified phospholipids: these spots were phosphate-positive only, no other spray reagents gave positive results. The structures of these polar lipids are not currently known, but PL3 has an $R_{\mathrm{f}}$ value identical to that of the major phospholipid of Thermus and Meiothermus species.

major phospholipid present in members of the genera Thermus and Meiothermus. The presence of MK- 8 as the predominant respiratory quinone is consistent with reports of MK-8 in members of the genera Thermus, Meiothermus (Hensel et al., 1986; Chung et al., 1997) and Marinithermus (Sako et al., 2003). MK-8 is also the dominant respiratory lipoquinone present in members of the genus Deinococcus (Embley et al., 1987; Ferreira et al., 1997). However, the presence of MK-9, albeit at only $5 \%$, appears to be a unique feature of the novel isolate in comparison with the genera Deinococcus, Thermus and Meiothermus. MK-9 was not reported in Marinithermus hydrothermalis (Sako et al., 2003). The presence of iso- and anteiso-branched fatty acids is a feature of members of the genera Deinococcus, Thermus, Meiothermus and Marinithermus (Embley et al., 1987; Ferreira et al., 1997; Donato et al., 1990, 1991; Sato et al., 2003). However, members of the genera Thermus, Meiothermus and Marinithermus described to date do not produce significant amounts of iso-unsaturated fatty acids, as strain $506^{\mathrm{T}}$ does. In contrast, members of the genus Deinococcus produce a number of isomers of isounsaturated fatty acids, although their distribution may differ between species. Members of the genera Thermus and Meiothermus described to date produce both phospholipids and glycolipids (Donato et al., 1990, 1991). Although members of the genus Deinococcus may also produce glycolipids in addition to a novel series of phosphoglycolipids (Embley et al., 1987; Ferreira et al., 1997), the latter are absent in members of the genera Thermus and Meiothermus. Strain $506^{\mathrm{T}}$ does not produce glycolipids in significant proportions, which makes it clearly distinguishable from members of the genera Thermus and Meiothermus. No information on phosphoglycolipids or glycolipids is available for Marinithermus hydrothermalis. The presence of the same major phospholipid (according to TLC studies) in strain $506^{\mathrm{T}}$ and members of the genera Thermus and Meiothermus is also consistent with the $16 \mathrm{~S}$ rDNA sequence data. However, the absence of glycolipids strengthens the case for placing the novel strain in a new genus.

The $\mathrm{G}+\mathrm{C}$ content of the DNA of isolate $506^{\mathrm{T}}$ was found to be $62.9 \mathrm{~mol} \%$. The similarity between the $16 \mathrm{~S}$ rRNA gene sequence of strain $506^{\mathrm{T}}$ and that of Marinithermus hydrothermalis JCM $11576^{\mathrm{T}}$ was $90 \cdot 3 \%$; similarity to sequences of members of the Thermus and Meiothermus branches was $87 \cdot 0-89 \cdot 6 \%$. The branching point of strains $506^{\mathrm{T}}$ and JCM $11576^{\mathrm{T}}$ changed with the algorithm and number and phylogenetic status of outgroup reference sequences, and often the two lineages do not cluster together. In some dendrograms, strain $506^{\mathrm{T}}$ was a deep branch in the Thermus clade (using a neighbour-joining algorithm with different Deinococcus species as an outgroup), while strain $506^{\mathrm{T}}$ branched deeply in the Meiothermus branch using the DeSoete algorithm with Aquifex species and deinococci as an outgroup (Fig. 3). In neither dendrogram did strain $506^{\mathrm{T}}$ branch within the

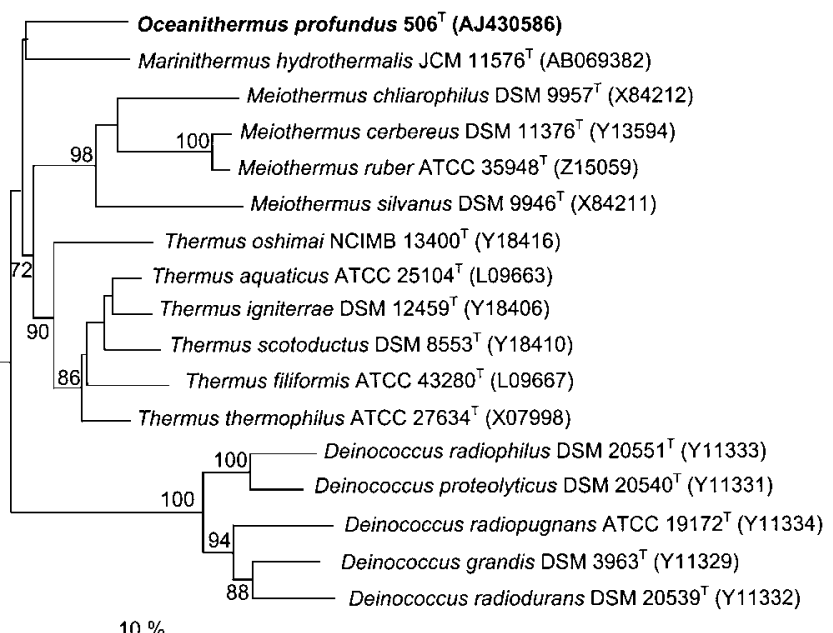

Fig. 3. Neighbour-joining dendrogram of $16 \mathrm{~S}$ rDNA relatedness, showing the position of strain $506^{\top}$ next to its phylogenetic neighbours, members of the genera Meiothermus, Thermus and Deinococcus in the Deinococcus-Thermus phylum of the Bacteria. Percentages of bootstrap support for branch points (1000 resamplings) above $70 \%$ confidence are indicated. Bar, 10 nucleotide substitutions per 100 sequence positions. The tree was rooted with the 16S rDNA sequences of Aquifex pyrophilus. 
radiation of either Thermus or Meiothermus. Only low bootstrap values were found for the branching point of strain $506^{\mathrm{T}}$ in each of the phylogenetic patterns obtained.

Because of its thermophily and metabolic flexibility, strain $506^{\mathrm{T}}$ is well adapted to the marine hydrothermal environment. Being microaerophilic, the novel isolate may gain significant advantages under conditions where oxygen is limited by its low solubility at high temperature and the reducing nature of hydrothermal fluids and gases. On the other hand, the ability of strain $506^{\mathrm{T}}$ to use nitrate as an alternative electron acceptor allows it to sustain growth even under anaerobic conditions, which may occur because of spatial and temporal variations of oxygen concentration in hydrothermal vent habitats. The range of compounds that can support growth of the novel isolate is very broad and includes not only organic nutrients derived from biogenic remains, but also non-fermentable substrates (acetate, propionate) produced by the metabolic activity of other inhabitants of hydrothermal vents, e.g. archaea of the genus Thermococcus and bacteria of the order Thermotogales. Finally, strain $506^{\mathrm{T}}$ may gain an advantage even under conditions of strong organic substrate limitation, switching from the chemoorganoheterotrophic type of metabolism to the chemolithoheterotrophic mode, utilizing molecular hydrogen of hydrothermal origin. Thus, its greater metabolic versatility may allow it to compete successfully with obligately anaerobic heterotrophs inhabiting the microbial community of deep-sea hydrothermal vents.

Phylogenetic analysis placed isolate $506^{\mathrm{T}}$ in the family Thermaceae. Indeed, it shares common phenotypic features with members of this family, including the characteristic cell wall structure, with a 'cobblestone' outer layer, the formation of 'rotund bodies', the possession of catalase and oxidase activities and the ability to grow anaerobically in the presence of nitrate, reducing it to nitrite. However, in contrast to all members of this group, strain $506^{\mathrm{T}}$, being microaerophilic, is not able to grow with oxygen at atmospheric pressure. It exhibits the ability to utilize a broader range of carbohydrates, organic acids and alcohols. Another significant characteristic of the metabolism of the novel isolate is its ability to grow lithoorganotrophically with molecular hydrogen as the electron donor. On the basis of the phenotypic and genomic differences and the distinct phylogenetic position of isolate $506^{\mathrm{T}}$, we propose a new genus, Oceanithermus gen. nov., with Oceanithermus profundus gen. nov., sp. nov. as the type species.

\section{Description of Oceanithermus gen. nov.}

Oceanithermus gen. nov. (O.ce.a.ni.ther'mus. L. n. oceanus the ocean; Gr. fem. n. therme heat; N.L. masc. n. Oceanithermus warmth-loving organism living in the ocean).

Cells are non-motile, Gram-negative rods, $0 \cdot 5-0 \cdot 7 \mu \mathrm{m}$ in diameter and of variable length. Moderate thermophile. Neutrophile. Adapted to the salinity of sea water. Microaerophile. Flagella and spores are not observed. Able to utilize a broad range of carbohydrates, some proteinaceous substrates, organic acids and alcohols. Capable of anaerobic growth with nitrate, which is reduced to nitrite. Capable of chemolithoheterotrophic growth with molecular hydrogen. Sole respiratory lipoquinones present are menaquinones, with MK-8 predominating; MK-9 may account for about $5 \%$ of the total. Fatty acids are iso- and anteisobranched; unsaturated iso-branched fatty acids are also present. Phospholipids are the only polar lipids present. The major phospholipid present has an $R_{\mathrm{f}}$ identical to that of the major phospholipid present in Thermus and Meiothermus species. The $\mathrm{G}+\mathrm{C}$ content of the DNA of the type strain of the type species is $62.9 \mathrm{~mol} \%$. $16 \mathrm{~S} \mathrm{rDNA}$ analysis places Oceanithermus in the family Thermaceae. The type species is Oceanithermus profundus.

\section{Description of Oceanithermus profundus sp. nov.}

Oceanithermus profundus (pro.fun'dus. L. gen. n. profundus of the abyss, the depths of the ocean).

Displays the following properties in addition to those given in the genus description. Filaments and 'rotund bodies' are formed by old cells grown on proteinaceous substrates. The optimal growth temperature is $60^{\circ} \mathrm{C}$. The optimal pH is $7 \cdot 5$ and the optimum salinity is $30 \mathrm{~g} \mathrm{l}^{-1}$. Oxidase- and catalasepositive. Oxidizes carbohydrates, starch, peptides, organic acids and alcohols. The chemical composition of the species is identical to that of the genus. The $\mathrm{G}+\mathrm{C}$ content of the DNA of the type strain is $62.9 \mathrm{~mol} \%$. The type strain, strain $506^{\mathrm{T}}\left(=\mathrm{DSM} 14977^{\mathrm{T}}=\right.$ VKM B- $\left.2274^{\mathrm{T}}\right)$, was isolated from a deep-sea hydrothermal vent of the East Pacific Rise.

\section{Acknowledgements}

This work was supported by INTAS grant 99-1250, RFBR grant 00-044894, the program 'Biodiversity' of the Russian Ministry of Industry, Science and Technology and a grant from the CNRS and RhônePoulenc. We thank the crews of R/V L'Atalante and the pilots of the DSV Nautile for their skill during the Amistad cruise organized by CNRS and Ifremer (1999).

\section{References}

Balch, W. E., Fox, G. E., Magrum, L. J., Woese, C. R. \& Wolfe, R. S. (1979). Methanogens: reevaluation of a unique biological group. Microbiol Rev 43, 260-296.

Bonch-Osmolovskaya, E. A., Sokolova, T. G., Kostrikina, N. A. \& Zavarzin, G. A. (1990). Desulfurella acetivorans gen. nov. and sp. nov. - a new thermophilic sulfur-reducing eubacterium. Arch Microbiol 153, 151-155.

Brian, B. L. \& Gardner, E. W. (1968). A simple procedure for detecting the presence of cyclopropane fatty acids in bacterial lipids. Appl Microbiol 16, 549-552.

Brock, T. D. \& Edwards, M. R. (1970). Fine structure of Thermus aquaticus, an extreme thermophile. J Bacteriol 104, 509-517.

Brock, T. D. \& Freeze, H. (1969). Thermus aquaticus gen. n. and sp. n., a nonsporulating extreme thermophile. J Bacteriol 98, 289-297. 
Cashion, P., Holder-Franklin, M. A., McCully, J. \& Franklin, M. (1977). A rapid method for the base ratio determination of bacterial DNA. Anal Biochem 81, 461-466.

Chung, A. P., Rainey, F., Nobre, M. F., Burghardt, J. \& Da Costa, M. S. (1997). Meiothermus cerbereus sp. nov., a new slightly thermophilic species with high levels of 3-hydroxy fatty acids. Int J Syst Bacteriol 47, 1225-1230.

Da Costa, M. S. \& Rainey, F. A. (2001). Family I. Thermaceae fam. nov. In Bergey's Manual of Systematic Bacteriology, 2nd edn, vol. 1, The Archaea and the Deeply Branching and Phototrophic Bacteria, pp. 403-404. Edited by G. M. Garrity. New York: Springer.

DeSoete, G. (1983). A least squares algorithm for fitting additive trees to proximity data. Psychometrika 48, 621-626.

Donato, M. M., Seleiro, E. A. \& Da Costa, M. S. (1990). Polar lipid and fatty acid composition of strains of the genus Thermus. Syst Appl Microbiol 13, 234-239.

Donato, M. M., Seleiro, E. A. \& Da Costa, M. S. (1991). Polar lipid and fatty acid composition of strains of Thermus ruber. Syst Appl Microbiol 14, 235-239.

Embley, T. M., O'Donnell, A. G., Wait, R. \& Rostron, J. (1987). Lipid and cell wall amino acid composition in the classification of members of the genus Deinococcus. Syst Appl Microbiol 10, 20-27.

Felsenstein, J. (1993). PHYLIP: Phylogeny inference package, version 3.5.1. Distributed by the author. Department of Genetics, University of Washington, Seattle, USA.

Ferreira, A. C., Nobre, M. F., Rainey, F. A., Silva, M. T., Wait, R., Burghardt, J., Chung, A. P. \& Da Costa, M. S. (1997). Deinococcus geothermalis sp. nov. and Deinococcus murrayi sp. nov., two extremely radiation-resistant and slightly thermophilic species from hot springs. Int J Syst Bacteriol 47, 939-947.

Hensel, R., Demharter, W., Kandler, O., Kroppenstedt, R. M. \& Stackebrandt, E. (1986). Chemotaxonomic and molecular-genetic studies of the genus Thermus: evidence for a phylogenetic relationship of Thermus aquaticus and Thermus ruber to the genus Deinococcus. Int J Syst Bacteriol 36, 444-453.

Jukes, T. H. \& Cantor, C. R. (1969). Evolution of protein molecules. In Mammalian Protein Metabolism, pp. 21-132. Edited by H. N. Munro. New York: Academic Press.

Mesbah, M., Premachandran, U. \& Whitman, W. B. (1989). Precise measurement of the $\mathrm{G}+\mathrm{C}$ content of deoxyribonucleic acid by highperformance liquid chromatography. Int J Syst Bacteriol 39, 159-167.

Miroshnichenko, M. L., Gongadze, G. A., Lysenko, A. M. \& BonchOsmolovskaya, E. A. (1994). Desulfurella multipotens sp. nov., a new sulfur-respiring thermophilic eubacterium from Raoul Island (Kermadec archipelago, New Zealand). Arch Microbiol 161, 88-93.

Miroshnichenko, M. L., Kostrikina, N. A., Chernyh, N. A., Pimenov, N. V., Tourova, T. P., Antipov, A. N., Spring, S., Stackebrandt, E. \&
Bonch-Osmolovskaya, E. A. (2003). Caldithrix abyssi gen. nov., sp. nov., a nitrate-reducing, thermophilic, anaerobic bacterium isolated from a Mid-Atlantic Ridge hydrothermal vent, represents a novel bacterial lineage. Int J Syst Evol Microbiol 53, 323-329.

Nichols, P. D., Guckert, J. B. \& White, D. C. (1986). Determination of monounsaturated fatty acid double-bond position and geometry for microbial monocultures and complex consortia by capillary GC-MS of their dimethyl disulphide adducts. J Microbiol Methods 5, 49-55.

Nobre, M. F., Trüper, H. G. \& Da Costa, M. S. (1996). Transfer of Thermus ruber (Loginova et al. 1984), Thermus silvanus (Tenreiro et al. 1995), and Thermus chliarophilus (Tenreiro et al. 1995) to Meiothermus gen. nov. as Meiothermus ruber comb. nov., Meiothermus silvanus comb. nov., and Meiothermus chliarophilus comb. nov., respectively, and emendation of the genus Thermus. Int J Syst Bacteriol 46, 604-606.

Rainey, F. A., Ward-Rainey, N., Kroppenstedt, R. M. \& Stackebrandt, E. (1996). The genus Nocardiopsis represents a phylogenetically coherent taxon and a distinct actinomycete lineage: proposal of Nocardiopsaceae fam. nov. Int J Syst Bacteriol 46, 1088-1092.

Sako, Y., Nakagawa, S., Takai, K. \& Horikoshi, K. (2003). Marinithermus hydrothermalis gen. nov., sp. nov., a strictly aerobic, thermophilic bacterium from a deep-sea hydrothermal vent chimney. Int J Syst Evol Microbiol 53, 59-65.

Skirnisdottir, S., Hreggvidsson, G. O., Holst, O. \& Kristjansson, J. K. (2001). Isolation and characterization of a mixotrophic sulfuroxidizing Thermus scotoductus. Extremophiles 5, 45-51.

Strömpl, C., Tindall, B. J., Jarvis, G. N., Lünsdorf, H., Moore, E. R. B. \& Hippe, H. (1999). A re-evaluation of the taxonomy of the genus Anaerovibrio, with the reclassification of Anaerovibrio glycerini as Anaerosinus glycerini gen. nov., comb. nov., and Anaerovibrio burkinabensis as Anaeroarcus burkinensis [corrig.] gen. nov., comb. nov. Int J Syst Bacteriol 49, 1861-1872.

Tamaoka, J. \& Komagata, K. (1984). Determination of DNA base composition by reversed-phase high-performance liquid chromatography. FEMS Microbiol Lett 25, 125-128.

Tindall, B. J. (1990a). A comparative study of the lipid composition of Halobacterium saccharovorum from various sources. Syst Appl Microbiol 13, 128-130.

Tindall, B. J. (1990b). Lipid composition of Halobacterium lacusprofundi. FEMS Microbiol Lett 66, 199-202.

Williams, R. A. D. \& Da Costa, M. S. (1992). The genus Thermus and related microorganisms. In The Prokaryotes, 2nd edn, vol. 1, pp. 3746-3751. Edited by A. Balows, H. G. Trüper, M. Dworkin, W. Harder \& K. H. Schleifer. New York: Springer.

Wolin, E. A., Wolin, M. J. \& Wolfe, R. S. (1963). Formation of methane by bacterial extracts. J Biol Chem 238, 2882-2888. 